\title{
Improvement of Gating Systems with the Purpose of Reducing Defects in Large-Size Castings from Gray Iron
}

\author{
${ }^{1}$ Dmitry A. Malinovsky, ${ }^{2}$ Nikolay N. Safronov, ${ }^{3}$ Lenar R. Kharisov \\ ${ }^{1-3}$ Kazan Federal University \\ Email:In271@mail.ru
}

Received: 23 ${ }^{\text {rd }}$ July 2019, Accepted: $10^{\text {th }}$ August 2019, Published: $31^{\text {st }}$ August 2019

\begin{abstract}
The article analyzes the types of castings defects. There are four groups of them: fit; conditionally fit, with small deviations from the established requirements; correctable marriage; incorrigible or final defects. The way to eliminate casting defects was to change the gating system. Despite the very large number of constructive types of gating systems, 4 classes are distinguished, differing by elements, as well as by hydraulic features of functioning. The article presents the technology of casting processes modeling. In this work the casting process modeling program LVMFlow was used. The LVMFlow system is used for computer modeling of processes that occur in the mold and for optimization of the casting manufacturing technological process. The core of the computer simulation of thermal and hydrodynamic casting processes of LVMFlow are the heat and mass transfer equations. Computer simulation allowed us to trace all the processes that occur in the metal during the filling of the mold, solidification and the occurrence of shrinkage defects. The results of modeling of the initial version of the gating system are presented. The defects such as shrinkage and erosion of the mold, the reject on which was $20 \%$, are found. When the proposed gating system of the siphon type was used, defects for shrinkage and erosion were absent for six months of the production of castings of this type.
\end{abstract}

\section{Keywords}

Gray Cast Iron, Casting, Casting Defects, Casting Rejects, Modeling, Gating System.

\section{Introduction}

Cast iron, in which most of the carbon is in a free state in the form of graphite, is called gray iron. Gray cast iron is soft, well machined with cutting tools. In kink it has a gray color. Gray cast iron has a low ductility, it can not be forged, as the graphite contained in it contributes to the splitting of the metal. Gray cast iron works much better in compression than in tension. Gray cast iron is produced by slow cooling after melting or heating. The melting point of gray iron is $1100-1250^{\circ} \mathrm{C}$. Typically gray iron contains $2.8-3.6 \%$ carbon, $1.6-3.0 \%$ silicon, $0.5-1 \%$ manganese, $0.2-0.8 \%$ phosphorus and $0.05-0.12 \%$ sulfur. Sulfur reduces the fluidity and strength of cast iron, increases its foundry shrinkage and complicates its welding. Phosphorus makes cast iron more fluidly fusible and improves its weldability, but increases its hardness and brittleness.

The disadvantage of gray iron is brittleness, preventing its use for the manufacture of machine parts subjected to shock loads. Gray cast iron is most widely used in mechanical engineering for the casting of various machine parts. It is quite well welded, especially with the use of preheating. It is little plastic and tough, but is easily machined, it is used for irresponsible parts and parts working for wear.

In the automotive industry crankcase, covers, brake drums, etc. are made of ferritic-pearlite cast iron, and cylinder blocks, sleeves, flywheels, etc. are made of pearlitic cast iron. Due to the low mechanical properties of gray iron castings and the ease of obtaining they are used for the manufacture of parts of less critical purpose, parts that work in the absence of shock loads, in particular, caps, pulleys, machine beds and presses are made of them [1].

\section{Problem Statement}

A casting defect refers to each individual product non-compliance with the established requirements. A product that has at least one defect is called defective. This means that at least one of the indicators of the quality of the casting has exceeded the maximum permissible value. The castings produced by any method are monitored for quality, the control is carried out by the workers of the foundry and the technical control department.

Depending on the degree of defects, all castings are divided into four groups:

1. Fit, fully meet all the established requirements of technical documentation and standards.

2. Conditionally fit, with small deviations from the established requirements (minor defects) that do not have a significant impact on the performance indicators of the casting or the product as a whole; castings are allowed for further processing and are used for their intended purpose with the permission of the main specialists of industrial enterprises after careful evaluation of defects.

3. Reparable defects - castings that have one or more disposable defects, after which they can be corrected, they can be allowed for further processing and use as intended.

4. An incorrigible or final defect - castings with such defects, the correction of which is technically impossible or economically inexpedient, or the quality of the correction of which cannot be checked [2].

The eliminability or irreparability of the defect is determined in relation to specific conditions of production and repair. Defects are categorized according to various criteria. For example, they can be obvious and hidden depending on the susceptibility of defects to detection. An obvious one is a defect detected by external examination (visual inspection), or 
a defect for the detection of which the relevant techniques and methods are provided in the regulatory documentation. Despite the impossibility of visual detection, such a defect is obvious, since using the prescribed flaw detection technique, it will certainly be detected. A hidden defect is a one that is not detectable under the above conditions and is not detectable by the instrumentation provided for control. Hidden defects are sometimes detected during the machining of castings or during the operation of products, as well as with additional defectoscopic control, methods and means not provided for in flow charts. It is the most undesirable and dangerous when a hidden defect manifests itself during the operation of the product that can cause an emergency situation [3].

According to GOST 19200-80 casting defects are divided into five main groups:

1. Discrepancy in geometry (14 types):

2. Surface defects (13 types)

3. Disorders in the casting body (16 types):

4. Inclusions (3 types)

5. Discrepancy in structure (4 types)

The most frequent defect is shrinkage shells and washout of the mold (fig. 1) for large-sized pouring, for example, such a casting as "Carter of the gear divider", the rejects of which are $20 \%$.

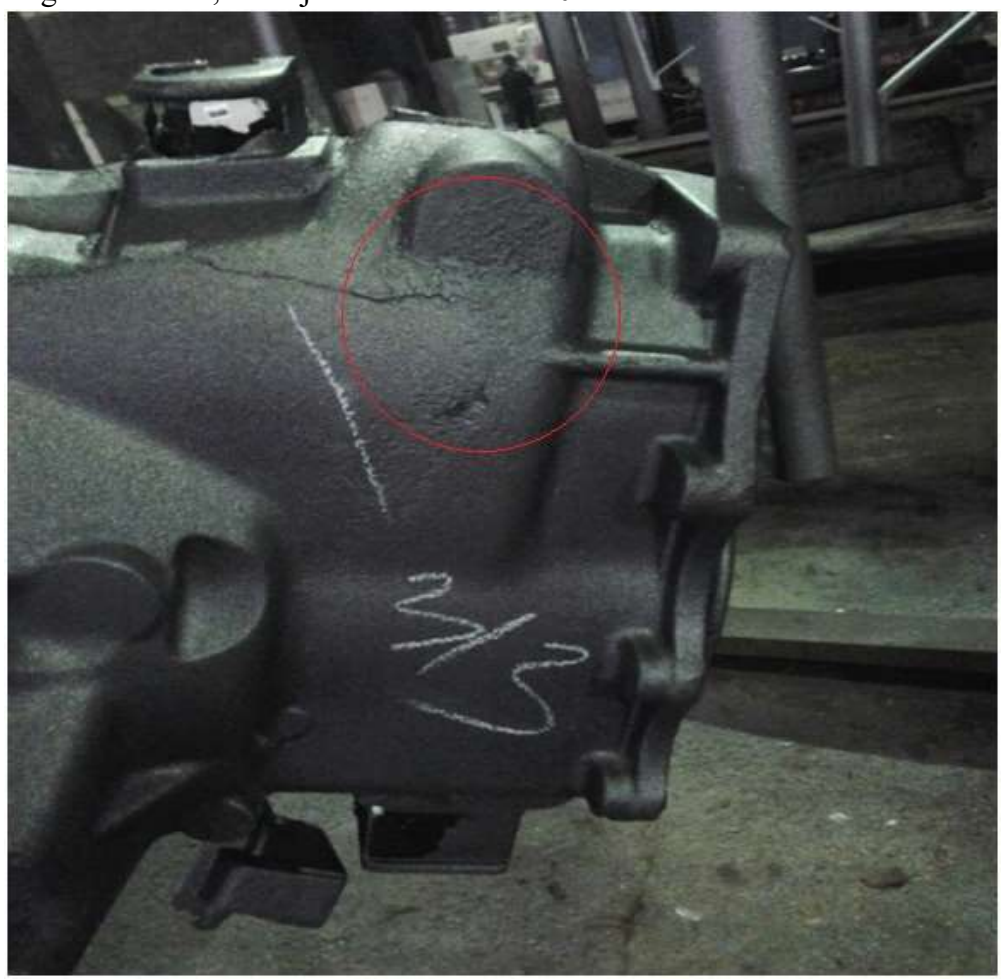

Figure 1: The Defects of the Casting "Carter of the Gear Divider"

\section{Experimental Procedures}

One of the most effective ways to eliminate cast defects is to change the gating system. As it is known from the fundamentals of hydrodynamics, the flow rate of a fluid flowing through a gating system is determined by the area of a narrow section of the system $\omega_{y_{3}}$ and the magnitude of the pressure of the liquid $H_{p}$. The smallest cross-sectional area of the channel, which determines the flow rate of the alloy in the system, is the bottleneck of the gating system. When pouring molds from ladles, the area of the bottleneck of the gating system, which guarantees the filling of the mold for the optimal time, is calculated by the formula:

$$
\omega_{\text {уз }}=\frac{G_{ж}}{\rho_{ж} \cdot \mu \cdot \tau_{\text {опт }} \cdot \sqrt{2 g+H_{p}}}
$$

where $\rho_{\varkappa}-$ the density of the melt, $\mathrm{kg} / \mathrm{cm}^{3}$;

$\mu$ - the flow coefficient of the gating system;

$H_{\mathrm{p}}$ - hydrostatic pressure, cm;

$g$ - the acceleration of gravity, $g=9.81 \mathrm{~cm} / \mathrm{sec}^{2}$;

$G_{\varkappa}$ - the mass of the liquid metal passing into the mold through the gating system, $\mathrm{kg}$.

A casting system is called closed if it simultaneously satisfies two conditions: the cross section of each channel is completely filled with melt and there is no vacuum in the fluid flow through a specific element of the system. The closed system provides the conditions for slag retention and non-metallic inclusions. If the channels of the gating system are not filled with metal, the slag inclusions and non-metallic impurities float to the surface of the liquid metal 
and are carried away into the cavity of the casting. If a vacuum occurs in the fluid flow, ejection of gases occurs, which become gas pockets in the castings. In order for the gating system to be closed it is necessary to be narrowed, i.e. along the flow of the alloy the cross-sectional areas of the elements of the system decrease. The speed of the alloy increases, reaching the highest value at the exit to the mold cavity. Despite the very large number of constructive types of gating systems, 4 classes can be distinguished, differing in elements, as well as in hydraulic features of operation.

The composition of gating systems of class I includes a gating bowl or a funnel and a riser (Fig. 2).

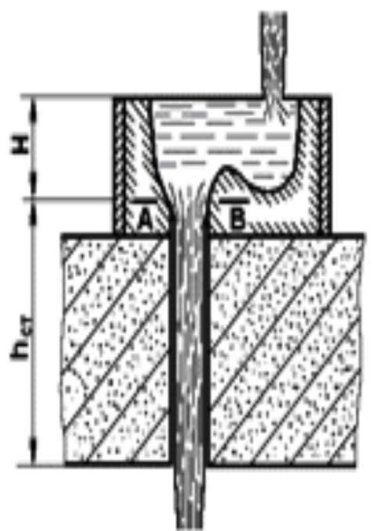

Figure 2: The Gating System of Class I

The bottleneck of the system of this class is in the upper section of the riser AB (Fig. 2). Estimated pressure $H p=H u+$ hcm; where $\mathrm{Hu}$ is the height of the metal level in the bowl. In this case, the dynamic pressure of the jet falling from the bucket is completely extinguished in the bowl. To ensure that the system is closed in the riser, it is made conical, tapering downwards. At the same time the jet completely across the entire height of the riser fills its cross-section. The bottleneck of the system in this case is located in the lower section of the riser. Class I systems are relatively rarely used in practice. As an example, a rain gating system can be given.

The gating system of class II consists of a funnel or a bowl, a drain and a feeder (Fig. 2).

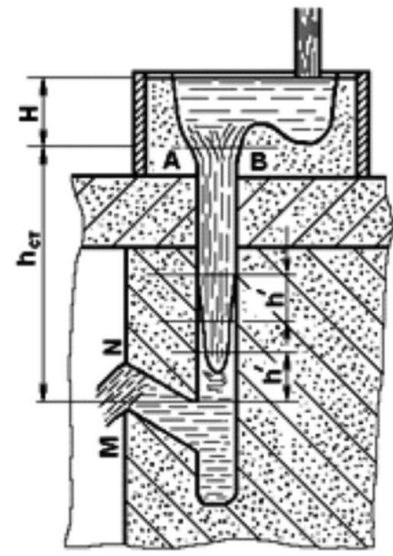

Figure 3: The Gating System of Class II

Liquid metal, accumulating in the lower part of the riser, begins to flow into the mold cavity through the feeder. If the cross-sectional area of the feeder is less than the area of the riser below, then the system will be closed in all elements. The common disadvantage of a class II system is the absence of a slag-trapping element in them. Therefore, their use often involves the installation of filter grids. Class II systems are often used with a vertical plane of a mold parting, for example, when casting into flaskless molds.

Gating systems of class III contain all main elements: a gating bowl or a funnel, a riser, a slag catcher and feeders. In this system the riser is quickly filled with an alloy, so it is closed in all elements. This type of gating system is most common when forms are cast with iron-carbon and many copper alloys. This system holds slag well. However, the speed of the alloy along the stream increases, reaching the highest value in the feeders, therefore these systems are not applicable for alloys prone to oxidation and foaming. To reduce the output flow rate, the bottleneck of the system is transferred to the slag trap or the lower section of the riser. 

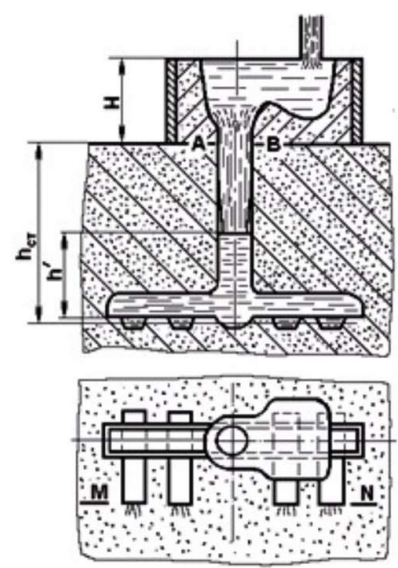

Figure 4: The Gating System of Class III

When filling of high castings occurs, it becomes necessary to supply melt at several levels. Gating systems of class IV have been developed for such purposes. In this case the alloy successively flows through the feeders to the surface of the melt rising in the mold, which ensures high-quality filling of the mold and directional solidification of the casting. However, the practical implementation of this mode of filling the form has specific requirements for the design and calculation of the gating system.

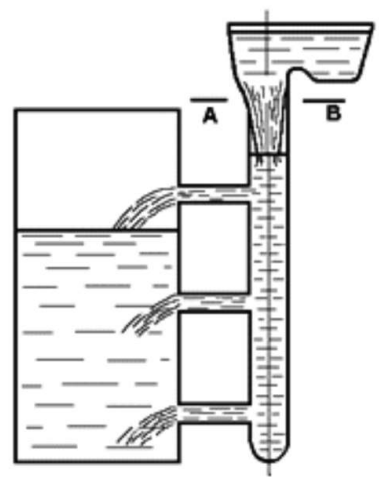

Figure 5: The Gating System of Class IV

They are designed so that at the beginning only feeders at the lower level act. The cross-sectional area of the lower feeder is determined so that the steady-state height of the alloy in the riser does not exceed the distance between two adjacent feeders. As the level of the alloy in the mold above the lower feeder rises, the level of the alloy in the riser rises. Simultaneous outflow of melt from feeders from all levels leads to oxidation and spattering of the metal, erosion of the walls of the mold, i.e. it does not provide high-quality filling of the mold. Therefore, systems of type IV are not used in practice.

Based on the characteristics of the casting formation "Carter gear divider", a siphon gating system with supply of metal into the mold cavity from below was selected.

The initial data for the simulation:

The casting No: 154-1770032-20 Carter

The alloy grade - SCh25

The alloy pouring temperature $-1420^{\circ} \mathrm{C}$.

The casting mass - $68.35 \mathrm{~kg}$

The mold material - molding sand

The number of castings on one link - 2

The number of castings in the form - 2

The form filling time, $\mathrm{sec}-25-35 \mathrm{sec}$ 


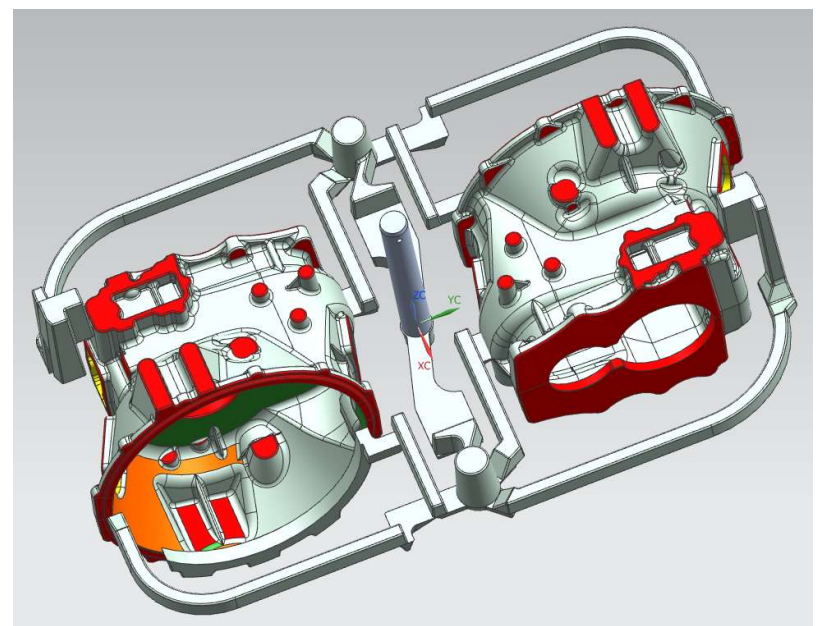

Figure 6: The Original Gating System of the Casting "Carter Gear Divider"

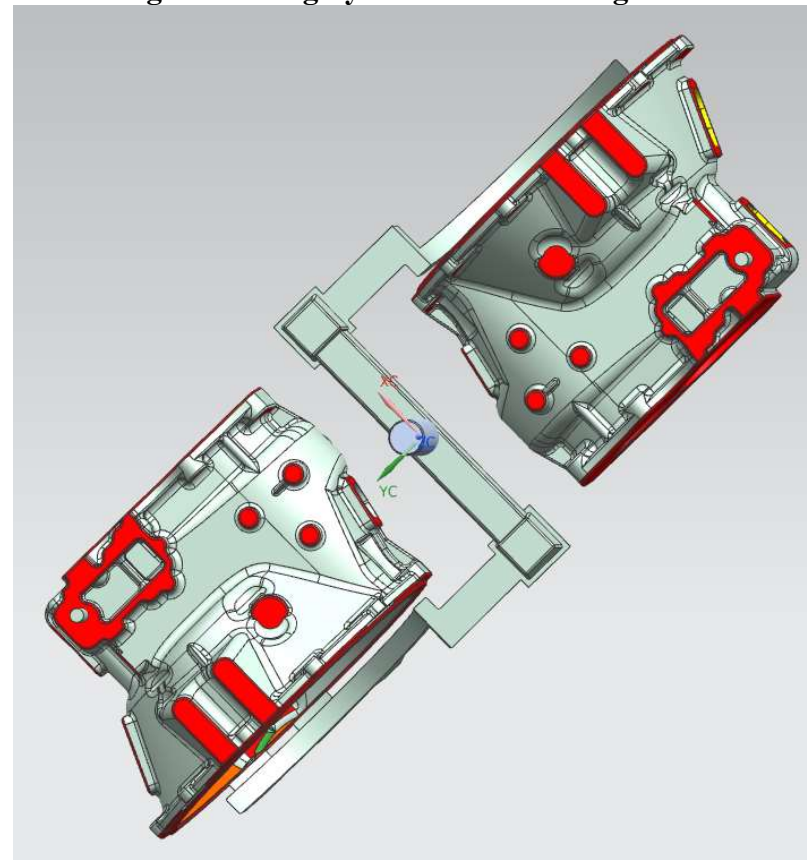

Figure 7: The Proposed Version of the Gating System of the Casting "Carter Gear Divider"

\section{Experimental Results and Discussion}

When developing of the foundry technology with the classic method by trial and error occurs, the solution of technological difficulties significantly slows down the process of mastering a new product and results in considerable material costs. In this regard at present computer simulation is used to speed up the process of foundry technology developing. Currently software products such as LVMFlow, ProCAST, MAGMASOFT, CastCAE, SOLIDCast, PoligonSoft, and WinCast are best known [5]. They differ in the used numerical methods, the analyzed types of castings, the volume of the material database, the used operating systems, the obtained results, the requirements for hardware support, etc. In this work the casting process modeling program LVMFlow was used. The LVMFlow system is used for computer modeling of processes that occur in the mold and for optimization of the casting manufacturing process. The core of the computer simulation of thermal and hydrodynamic casting processes of LVMFlow is the heat and mass transfer equations. LVMFlow is based on the volume control method and allows you:

- to observe the mold filling with metal,

- to calculate the temperature fields of the casting and mold,

- to calculate the field of the liquid phase,

- to calculate the velocity field,

- to calculate convective currents,

- to calculate the pressure field,

- to evaluate possible defects in the casting,

- to calculate stresses and strain of the casting, 
- to evaluate the operation of filters,

- to take into account the repeated use of the mold,

- to develop the technology of LPD,

- to calculate the size of the head metals and gating system,

- to take into account the behavior of the gas in the mold cavity during filling,

- to predict air trapping during the pouring process,

- to select sizes of isothermal and exothermic shells for head metals

The analysis of the technological process of castings manufacturing in the computer simulation system of casting processes LVMFlow consists of the following techniques and steps:

1. Conversion of casting geometry to LVMFlow format.

2. Creating a calculated finite-volume grid.

3. Setting the properties of materials.

4. Setting of limiting conditions.

5. The calculation of temperature fields.

6. Control of changes in design parameters.

7. Calculation of stresses and strains in the casting.

Computer simulation allows you to observe all the processes that occur in the metal during the filling of the mold, solidification and the occurrence of shrinkage defects [6-10].

Figure 8 presents the simulation results of the original version of the gating system. In the marked places such defects as shrinkage and erosion of the mold were observed, their rejects were $20 \%$.

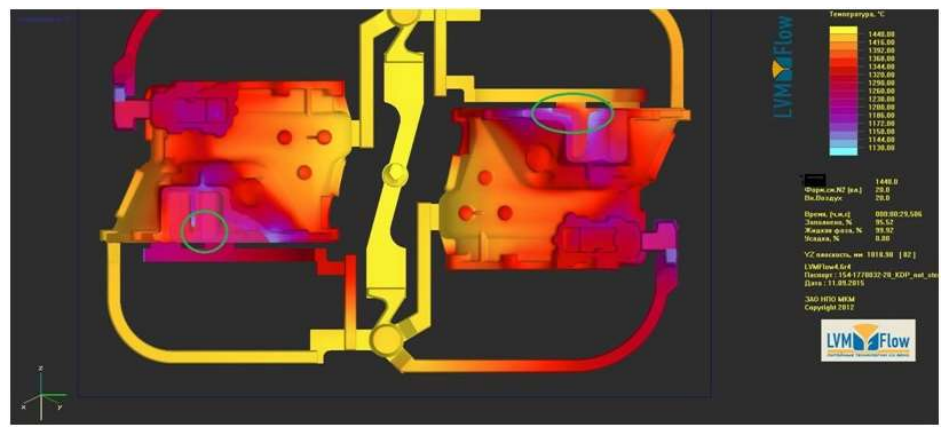

Figure 8: The Simulation Results of the Original Version of the Casting System of the Casting "Carter Gear Divider"

Fig.9 presents the simulation results of the proposed variant of the gating system.

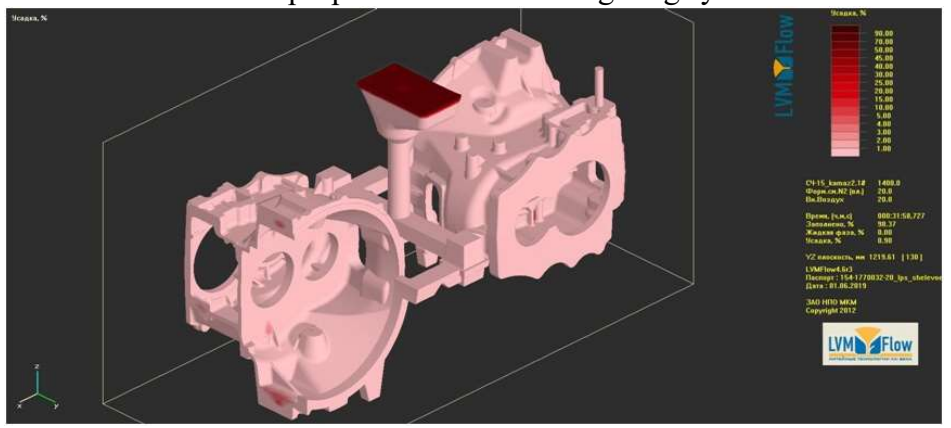

Figure 9: The Simulation Results of the Proposed Version of the Casting System of the Casting "Carter Gear Divider"

When the siphon gating system was used, the rejects on such defects as shrinkage and erosion over 5 months of 2019 amounted to $0 \%$.

\section{Conclusions}

Using the LVMFlow package allowed to reduce the role of the natural experiment, which reduces the cost of developing the casting technological process; make castings of high quality, complex configuration, which do not require the correction of defects; increased the professional level of the technologist-caster. As a result of 3D modeling it was found that for large-sized "Carter" type castings it is more expedient to use a siphon gating system, which has allowed a significant reduction in the casting rejects.

\section{Acknowledgements}

The work is performed according to the Russian Government Program of Competitive Growth of Kazan Federal University. 


\section{References}

1. Gini E.C., Zarubin A.M., Rybkin V.A. Foundry technology. Special types of casting / Publishing center "Academy", 2005. $-352 \mathrm{p}$.

2. Mogilev V.K. Reference bookmaker / M .: Mashinostroenie, 1988, 272 p. (In Russian).

3. Stephan Hasse. Modeling and microstructure defects: detection, Interpretation and avoidance of casting and microstructure defects in the production of cast components / Schiele und Schön, 1999. - p 289.

4. Grigoriev V.M. Development of manufacturing technology castings: Proc. manual / V.M. Grigoriev. - Khabarovsk: FEDUPS Publishing House, 2004. - 67 p.

5. ProCast / V.P. Monastyrsky, A.V. Monastyrsky, E.M. Levitan // Foundry. - 2007. - № 9. - p. $29-34$.

6. G.N. Safronov, N.N. Safronov, L.R. Kharisov, SHS ferroaluminum obtained from the disperse waste of engineering, Materials Science Forum, 2016.

7. Yakovleva D.M., Mukhametzyanova G.F., Kharisov L.R. The Research of Stresses in the Molds of Injection Molding Machines / Procedia Engineering, 2016. - Vol.150, p.453-457

8. Safronov G.N., Safronov N.N., Kharisov, L.R. The Corrosion-resistant high-silicon cast iron chemical engineering components / Chemical and Petroleum Engineering. - 2015. Vol.51, Issue 1-2, p.142-144.

9. Safronov G.N., Safronov N.N., Kharisov L.R (2015 The use of SHS-process slag for the preparation of foundry sand. J IOP Conference Series: Materials Science and Engineering 86:1-4. doi:10.1088/1757-899X/86/1/012023

10. Safronov N.N., Kharisov L.R., Safronov G.N. The Aluminum-Alloyed Cast Iron with Compact Graphite Inclusions from Fine Production Wastes / Russian Metallurgy (Metally), 2017. - Issue 13, p.1207-1209. 